\title{
Updating Ravenstein: Internal Migration as a Driver of Regional Population Change in the Wider South East of England ${ }^{*}$
}

\author{
Tony Champion
}

\begin{abstract}
Key among Ravenstein's "laws", derived from extensive analysis of mid$19^{\text {th }}$ century migration patterns in the British Isles, are that the majority of migrants go only a short distance and that migration proceeds stepwise as a sequence of localised population shifts towards the principal centres of commerce and industry. This paper tests these two laws in the $21^{\text {st }}$ century context of counterurbanisation by reference to migration taking place within the Wider South East (WSE) of England, being the region dominated by deconcentration pressures emanating from London. It comprises two sets of empirical analyses using migration data for the period 20012016. Firstly, these data are aggregated to a set of broadly concentric rings around this core and analysed to reveal how much of the net outward shifts of population produced by this migration arises from net movement taking place between adjacent rings as a type of cascade as opposed to leapfrogging directly from the core into a non-adjacent ring. Cascading is found to predominate at this scale, confirming the continued importance of shorter-distance moving. Secondly, the migration data are rendered into a Travel to Work Area (TTWA) framework to examine the extent to which these subdivisions of the WSE perform a type of entrepôt role in helping to shift population outwards from London. Drawing on Ravenstein's concepts of counties of "transfer" and "absorption", two measures are developed for revealing how the net inflow to a particular TTWA from rings closer to the core compares numerically with the net outflow from that TTWA to the rings further away from it. The derived transfer and absorption rates are then used to classify the TTWAs into four groups according to whether their scores on each are above or below average. It is found that a TTWA's role varies according to two main dimensions: the concentric zone to which it belongs and the radial sector out of London in which it is located, notably whether the sector has a coastal or landward border.
\end{abstract}

Keywords: Short-distance migration · Stepwise migration · Transfer rate • Absorption rate $\cdot$ South East England

\footnotetext{
This article belongs to a special issue on "Internal Migration as a Driver of Regional Population Change in Europe: Updating Ravenstein".
} 


\section{Introduction}

This paper examines how internal migration redistributes population across an extensive region dominated by London and analyses the centrifugal population movements emanating from that city, focusing on the period 2001-2016. It builds on a study of the Wider South East (WSE) of England that identified deconcentration as the largest and most consistent of the three main currents of migration affecting its spatial population dynamics in recent decades, alongside a fading North-South drift and a growing net inflow from abroad (Gordon et al. 2018). Impressively, the findings resonate considerably with the results of Ravenstein's pioneering analyses of within-UK migration some 130 years earlier, especially his two "laws" about most migrations taking place over short distances and about migration shifting population in a stepwise manner. It might have been expected that the huge changes that have taken place in demography, economy, society and technology since Ravenstein's analyses of data from the 1871 and 1881 Censuses - not least as reflected in the main current of internal migration no longer being towards "the main centres of commerce and industry" (part of his first law, see below) but away from them would have substantially weakened the relevance of these two generalisations, but this turns out not to be the case.

The paper begins by recalling Ravenstein's legacy, notably in terms of those two laws of migration but also concerning the migration patterns that he identified for the WSE. This sets the scene for the analysis of the within-UK migration flows affecting the WSE in the twenty-first century. For this, a two-fold geographical framework is adopted. The first involves dividing the UK into broadly concentric rings around London, looking to see how much of the city's net out-migration occurs in the form of relatively short steps between adjacent rings as opposed to longer-distance leapfrogging through direct exchanges between London and the more distant rings. The second framework involves assembling the migration data at the level of the WSE's Travel To Work Areas (TTWAs), enabling us to differentiate the places that are most intensely involved in the regional deconcentration process from those which accommodate more of their migrant inflow and thereby reduce the need for the further outward movement of population.

As the paper proceeds, it becomes clear that Ravenstein's laws about shortdistance and stepwise migration are highly applicable to the way in which the WSE's deconcentration current has been operating in recent years. Indeed, that current - previously conceptualised in terms of the "counterurbanisation cascade" (Champion/Atkins 1996; Champion 2005; see also Plane et al. 2005) - had already been likened by Ravenstein to the effect of "a cistern of water after the tap has been turned on" (Ravenstein 1889: 286). The analysis also draws on his idea of "counties of absorption" in devising a measure of the extent to which a place accommodates net migration from some parts of the country without this leading to the displacement of residents to elsewhere and also on his notion of "counties of passage" which are active in transferring population over space without any significant net change in their own resident numbers. At the same time, Ravenstein's approach is essentially descriptive of the patterns and, where he does venture into more explanatory 
mode, his comments tend to be lacking in a firm evidence base. Here, too, the paper follows his lead in merely speculating on the principal dynamic behind the migration patterns observed and briefly suggesting what further research is needed.

\section{Ravenstein's legacy}

It might be deemed unnecessary to recall here the contribution of Ravenstein to migration studies, so fundamental has this been and so fully has it been documented in other studies, as demonstrated by Greenwood's (2019) review of his legacy. In the context of this journal's special issue subtitled "Updating Ravenstein", however, it is very important to be explicit about what it is that the present paper is aiming to update. This is partly because the migration literature has been dominated by studies aimed at testing the seven "laws of migration" as set out formally in his 1885 paper (Ravenstein 1885: 198-199) and developed further by Lee (1966). This preoccupation has, as pointed out by Greenwood, led to the downplaying of Ravenstein's roles in anticipating the gravity modelling of migration and the concept of intervening opportunities, as well as ignoring his appreciation of the distorting effect on migration rates of having to use statistical reporting units that differ greatly in geographical size and shape. But the most important reason for recapitulating Ravenstein's contribution here is that the present paper focuses on a part of the world which features strongly in his descriptions of migration patterns, so there is the possibility of making comparisons between then and now.

In terms of Ravenstein's laws, it is the first two of these that are found to be of most relevance to this study of the WSE's recent migration trends, as just mentioned. In his own words (Ravenstein 1885: 198-199):

"1. ... the great body of our migrants only proceed a short distance, and ... there takes place consequently a universal shifting or displacement of the population, which produces 'currents of migration' setting in the direction of the great centres of commerce and industry which absorb the migrants.

2 . It is the natural outcome of this movement of migration ... that the process of absorption would go on in the following manner:- The inhabitants of the country immediately surrounding a town of rapid growth flock into it; the gaps thus left in the rural population are filled up by migrants from more remote districts, until the attractive force of one of our rapidly growing cities makes its influence felt, step by step, to the most remote corner of the kingdom."

This then is the basis of the twin concepts that concern us most in the present paper, namely that most migration is short-distance and that a broader shift in population distribution therefore occurs through a stepwise sequence of population shifts rather than through longer-distance movement of individuals directly from the areas of net out-migration to those of net in-migration.

Further, there are two aspects of Ravenstein's approach to studying migration that need to be made clear before summarising his observations on population shifts affecting London and its wider region. One is that his data refer to life-time 
migration owing to the fact that, unlike nowadays, the censuses of his time did not ask for people's whereabouts at a single previous point in time like one or five years before the census but instead recorded their birthplace. This means that any change in place of residence indicated by comparing place of census enumeration with that of birth could have taken place several years, if not decades, before the census and indeed might have involved several separate moves over the intervening period. The second aspect is that birthplace was provided in no more detail than the county level and also, as Ravenstein was at pains to point out, this is so only within each of the three "kingdoms" of England \& Wales, Scotland and Ireland, such that people enumerated in one of these three but born elsewhere in the British Isles are given only their country of origin and not the county. This means that Ravenstein's analysis is restricted to inter-county movement within each of these three areas, i.e. not covering local residential mobility and also not having the benefit of a full countylevel migration matrix for the UK.

Even with these restrictions, however, Ravenstein was able to draw on copious evidence in support of his conclusions about the importance of short-distance and stepwise migration, as can be amply demonstrated by reference to his observations on south-eastern England. This can be seen not only in his most commonly cited 1885 paper but also from his initial work which took the form of three papers in successive monthly issues of The Geographical Magazine (July, August and September 1876), these shortly afterwards being brought together in a 56-page essay entitled "The Birthplaces of the People and the Laws of Migration" and published as one of a series of Census of the British Isles 1871 reports (Ravenstein 1876). Indeed, this laid a great deal of the groundwork which was subsequently refined in his 1885 paper and updated by use of data from the 1881 Census. Here he separated the counties into "two great classes" - those with out-migration higher than the average rate for their country and those with lower rates - and then disaggregated places' populations by birthplace, thereby leading him to infer the process of stepwise migration. The latter is done not only for counties but also for a number of towns, though as just mentioned the detail of migrants' origins is limited to county within kingdom.

In relation to the WSE, it is not surprising to find that one of the places registering the greatest net in-migration according to the 1871 Census is London, this defined in "metropolitan" terms to include parts of the adjacent counties of Middlesex and Surrey (Ravenstein 1876: 18). Similarly, it is London that he puts forward as the prime example of the stepwise "recruiting process" (Ravenstein 1876: 20). He finds that counties adjacent to London have relatively larger non-native populations than those further away, symptomatic of "the devouring process that is going on in London" (Ravenstein 1876: 20) and the replacement of these adjacent counties' populations by in-migrants from further afield. He then provides (Ravenstein 1876: 21) a breakdown of London's residents by where they were born, with the largest contingents originating in two broadly concentric "metropolitan zones" around the capital, 317 thousand from the first of these (comprising Middlesex, Surrey, Kent, Essex, Bucks and Herts) and 290 thousand from the second (comprising the rest of the WSE plus Northants). The former is equivalent to 15.5 percent of that zone's 
population and the latter 10.4 percent, showing how the migration rate falls off with distance from the destination.

Turning to Ravenstein's 1885 paper, this not only updates these types of analysis with data from the 1881 Census, but also furnishes additional perspectives on London's migration. In particular, there is fuller attention to migration "currents", building up to his fourth law that "Each major current of migration produces a countercurrent" (Ravenstein 1885: 199). He notes (Ravenstein 1885: 187) that "In the case of metropolitan London, both the main and the counter-currents flow with considerable vigour", with almost 585 thousand London natives living elsewhere in England and Wales in 1881 compared with the total flow into London of 1164 thousand, giving an outflow of 50 per 100 in-migrants. He also observes that the outflow is more localised than the inflow, with an overall outflow/inflow ratio of 82 per 100 for the group of counties immediately surrounding London and with "extra-metropolitan Surrey" posting a ratio of 105, i.e. receiving more people from London than it sent to it (Ravenstein 1885: 188). This latter observation leads Ravenstein to remark: "Many, if not most of them, have merely removed to what are actually suburbs and can hardly be said to have left the metropolis" (Ravenstein 1885: 188). Otherwise, the main currents are all Londonward, at least for the county groupings shown in Ravenstein's table.

This observation is reinforced by the evidence of Ravenstein's plotting of "currents of migration" on a hand-drawn map of the British Isles (1885, Map 5, between pp 182 and 183). In the immediate vicinity of London, the only arrow pointing away from London is that to Surrey, as just mentioned. The map also helps to illustrate the stepwise nature of the Londonward shift in population. This is most conspicuous in the case of the north-eastern corridor into London, where the main current from Essex is to London, that from Suffolk is to Essex and that from Norfolk is to Suffolk. Another key corridor is from the west, with currents from Cornwall to Devon, then Devon to Dorset and Somerset, from there to Hampshire and on to Surrey. For the English Midlands, however, the pattern is less clear, with more of the arrows there pointing northwards to the other main national centre of economic growth located primarily in northern England. His example of Warwickshire (Ravenstein 1885: 194) is particularly interesting in this context, because this county acts as a feeder to both these poles of attraction, yet the county has been able to maintain a positive migration balance, with its net loss of 32 thousand to these two growth areas being more than made good by its net gain from elsewhere. As such, while classified as a "county of absorption" (Ravenstein 1885: 194), Warwickshire also bears the hallmarks of Ravenstein's "counties of passage" that act like an entrepôt in transferring people across space, similar to his archetypal example of Peebles within Scotland (Ravenstein 1885: 188).

\section{$3 \quad$ Studying the WSE's $21^{\text {st }}$ century patterns of migration}

As stated above, the central question which this paper seeks to answer is the degree of similarity between the WSE's current migration experience and the $19^{\text {th }}$ century 
patterns observed by Ravenstein. As part of this task, the aim is to investigate the extent to which his first two laws have stood the test of time and, at the same time, see what extra insights can be obtained by applying indicators derived from his ideas about places playing different types of roles in relation to migration, notably with some serving mainly as places of passage by transferring population over wider regions while others work to slow down this redistributive process by absorbing much of their migrant inflow. This section briefly reviews the massive changes that have taken place between the two eras and outlines the analytical approach adopted for this study.

\subsection{The changing context}

It goes without saying that there is a huge time lapse between the two eras. As noted above, it is already 130 years since the publication of Ravenstein's final paper in 1889 , but it is very nearly a century and half since the 1871 Census on which he based his first (1876) paper and even longer since much of the lifetime migration recorded by the 1871 and 1881 Censuses will have actually occurred. One substantial change is that, as the economy of the UK's manufacturing and mining heartlands has weakened, the national capital has increasingly become the single pivot around which the nation's migration system revolves (Coombes/Charlton 1992). As illustrated most compellingly by Fielding's (1992) "regional escalator" hypothesis, London acts as a major attractive force for young adults from all over the country who are lured there by better job prospects and faster career progression than elsewhere in the UK but who later in their working lives or at retirement may decide to trade in their gains of human and financial capital for better-quality and lower-cost environments elsewhere (see also Fielding 1993; Champion et al. 2014). Their destinations tend to be less distant from London than the source areas of the young adults, much of it taking place as extended suburbanisation similar in form to, but on a far broader canvas than, that noted by Ravenstein for non-metropolitan Surrey (see above) but also with a significant element actively seeking out more rural locations as "counterurbanisation" migration (Champion 1989: 1; see also Boyle/Halfacree 1998; Lomax/ Stil/well 2018).

These developments are responsible for the biggest change since Ravenstein's day, namely the complete reversal of the main internal migration current affecting the WSE. London now records a negative balance of within-UK migration and has been doing so for many decades (Champion 2016; Stil/well et al. 1992). Indeed, in keeping with some other major cities around the developed world, most notably New York, this was most apparent in the later 1960s and 1970s when absolute population decline was taking place, posing major fiscal challenges to city governance. In London's case, this process was reinforced by a programme of planned overspill to a ring of New and Expanded Towns situated beyond its extensive (25-40km wide) Green Belt (Champion 2002). London's population began to grow again in the late 1980s, but this reversal had rather little to do with changes in its within-UK migration, being driven primarily by rising immigration from abroad and a switch from natural decrease to the large surplus of births over deaths that prevails now (Gordon 
et al. 2018). If London's current patterns of within-UK migration were to be plotted on a county map like Ravenstein's, a vast majority of the arrows would be pointing away from London rather than towards it.

It is this major reversal in the overall pattern of internal migration affecting the WSE that primarily prompts the question as to how relevant Ravenstein's insights are for nowadays, this along with other examples of change since his time that might be thought to make longer-distance moving much easier than then, not least improved infrastructure for transportation and better information about more distant places. Can it still be the case that the currents of internal migration that are redistributing population across the extensive region around London are mainly composed of moves between adjacent areas rather than in the form of longer-distance leapfrogging to more distant destinations across intervening areas that now include a Green Belt where new urban development is highly restricted? In a nutshell, in this very different context, how tenable are Ravenstein's laws about the importance of short-distance migration and about migration tending to redistribute population in a stepwise manner?

\subsection{Data and methods}

This study addresses these questions using migration data for 2001-2016 derived from the NHS's Patient Register Data System (PRDS) by Office for National Statistics (ONS), which compares people's addresses - as notified to their doctors - between annual downloads and therefore records population movement in the form of yearly address "transitions". More recently, ONS has introduced counts of all moves ("events") using an extract from the NHS's Personal Demographic Service, but these are not directly comparable with the previous series (see ONS 2019, section 5). The NHS-derived migration data give the numbers of people who have changed address between each local government area and every other one in England and Wales and also their total exchanges with Scotland and Northern Ireland.

The PRDS-derived dataset is considered to be of high quality, but with two caveats. One concerns its reliance on migrants registering their change of address, as this process tends to be less swift for healthier people, most notably young adult males, but it will eventually occur after a time lag. Secondly, there have been some methodological improvements in the dataset since 2001, notably in trying to achieve more comprehensive coverage of students' moves to and from higher education. In the present study, though, both these issues are sidestepped by not examining trends over time and instead analysing a single 15-year period spanning the migration recorded for the year beginning in July 2001 (when the series began in its present form) through to that ending in June 2016.

The main analyses in this study are based on two sets of origin-destination migration matrices aggregated from these ONS data. One divides the UK into five zones with London being surrounded by four broadly concentric rings. This follows Ravenstein's lead in identifying "metropolitan zones" around the capital (see section 2, above). The other divides the WSE into its constituent TTWAs (see ONS 2016, for details). These provide a finer grain of analysis than Ravenstein's counties 
and indeed better represent the regional space economy in terms of both labour and housing markets. The only difference from the official TTWA geography is that these must be defined on the basis of the best fit of local government area because of the migration data being available in no more geographical detail than these (see above). Further details of these two geographical frameworks are provided in the relevant sections of the results below, namely 4.1 and 4.2 respectively.

Finally, again inspired by Ravenstein, two sets of measures of a place's role in redistributing population have been developed for the purposes of this study. One of these, building on his notion of "counties of absorption", relates to the extent to which a place accommodates the deconcentration current. This takes three forms: "absorption volume" is defined as the net migration inflow from concentric zones nearer London minus the net outflow to the rings further away from it, while "absorption level" is the volume expressed as a percentage of the net inflow and "absorption rate" refers to the volume as a percentage of the number of the place's residents. The second relates to Ravenstein's concept of "counties of passage", i.e. places which are heavily involved in transferring population over space without seeing their own population size altering appreciably in the process. Here the sum of the net inflow to a place from zones nearer London and the net outflow to zones further away from the capital is designated "transfer volume", which is then transformed into the "transfer rate" by reference to the place's population size. Higher values of the rate denotes a stronger role in redistributing population outwards across the region, while the volume can also be used to rank places according to their share of the region's overall deconcentration.

\section{$4 \quad$ Results}

\subsection{The five-ring perspective}

This section presents the results of the empirical analysis of the WSE's within-UK migration for 2001-2016 on the basis of the five-ring geography introduced in section 3.2 and depicted in Figure 1. London itself is defined in terms of the area currently administered by the Greater London Authority (GLA). The rest of the WSE comprises two rings, the inner ring reprising the concept of Outer Metropolitan Area (OMA) as developed for planning purposes in the 1960s and the other labelled the Outer Wider South East (OWSE). Lying beyond the WSE boundary are two further zones, namely a Fringe comprising the areas that are, as will be seen, the next most affected by metropolitan influence and finally the Rest of the UK.

Before examining the results of the migration analysis in detail, Table 1 sets the scene by outlining the broader picture of population change for this five-ring geography for the study period 2001-2016. It shows that there is no overall deconcentration of population from London as the growth rate of the latter exceeds that of the three surrounding rings by around half as much again, with the rest of the UK posting an even slower increase than these. At the same time, London's strong growth can be seen to be entirely due to a combination of natural increase and net immi- 
Fig. 1: The five rings

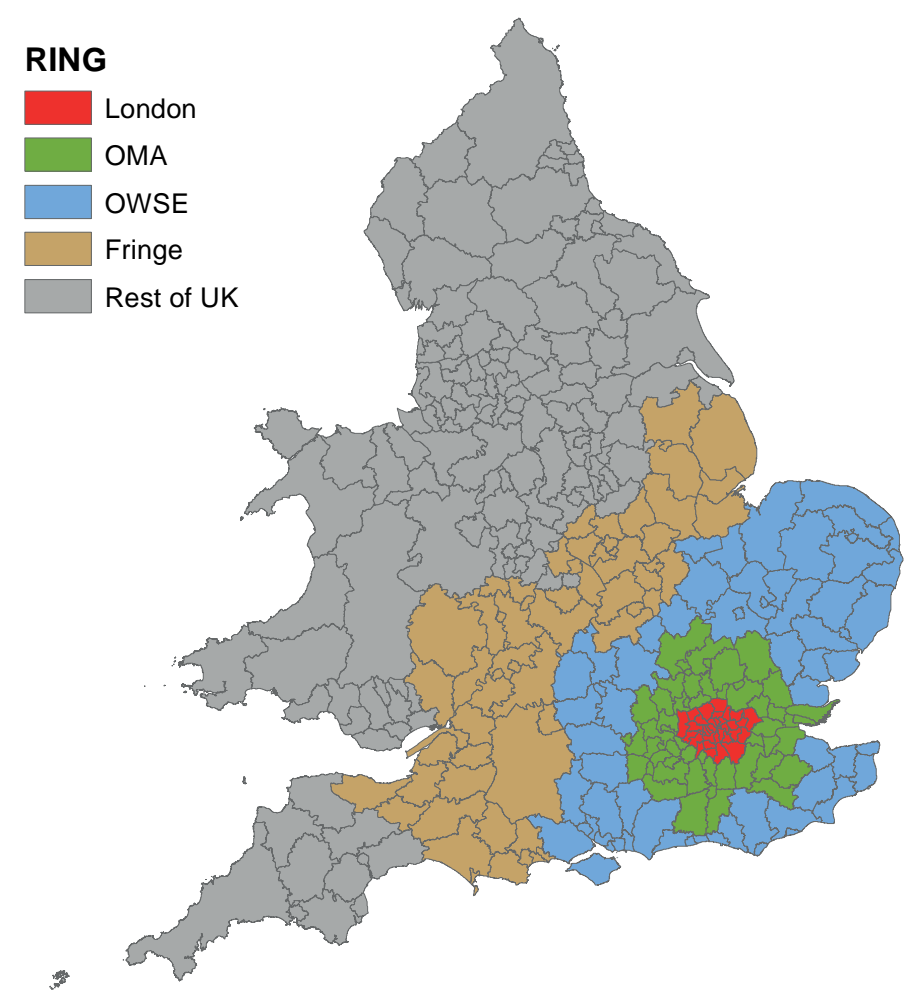

Note: Each ring is an aggregation of the local government areas shown, see text. OMA Outer Metropolitan Area, OWSE Outer Wider South East. The WSE comprises London, OMA and OWSE. Rest of UK also includes Scotland and Northern Ireland.

Source: based on the classification developed by Gordon et al. 2018.

gration from abroad: it loses substantially through its migration exchange with the UK. In absolute terms, the latter was averaging roughly 71 thousand a year over the 15-year period, compared to net immigration of 96 thousand and natural increase of 73 thousand. The situation seems highly reminiscent of Ravenstein's cistern-andtap metaphor, though with overspill only partially offsetting the supply coming from those two taps.

The other significant feature of Table 1 is that London's net out-migration to the rest of the country would seem to have had a very much smaller impact on the immediately adjacent ring than on the next two zones further away. The OMA's rate of net within-UK migration gain is less than one quarter of the rates for both the OWSE and the Fringe beyond. In absolute terms, this translates into a net gain of barely 5 thousand a year for the OMA, compared to net gains of 28 and 26 thousands a year respectively for the next two rings out from London. On this basis, one might conclude that it is primarily the intermediate distances from London that have provided 
Tab. 1: Population change and its main components for the UK's five rings: average annual change, $2001-2016, \%$ rate (compound)

\begin{tabular}{lcccc}
\hline Zone & $\begin{array}{c}\text { Natural } \\
\text { change }\end{array}$ & $\begin{array}{c}\text { International } \\
\text { migration }\end{array}$ & $\begin{array}{c}\text { Within-UK } \\
\text { migration }\end{array}$ & $\begin{array}{c}\text { Overall } \\
\text { change }\end{array}$ \\
\hline London & 0.92 & 1.22 & -0.91 & 1.22 \\
Outer Metropolitan Area (OMA) & 0.42 & 0.28 & 0.08 & 0.80 \\
Outer Wider South East (OWSE) & 0.15 & 0.30 & 0.36 & 0.82 \\
Fringe & 0.16 & 0.27 & 0.35 & 0.80 \\
Rest of UK & 0.17 & 0.26 & 0.04 & 0.50 \\
UK & 0.29 & 0.39 & 0.00 & 0.70 \\
\hline
\end{tabular}

Note: Numbers may not sum due to rounding. Also, 'overall change' includes 'unattributable changes' arising from adjustments following the 2011 Census, as well as the effect of methodological and administrative changes.

Source: Own calculations from ONS data.

the main destinations for its migration overspill, with shorter-distance population movement out of the capital being much less important.

A very different picture, however, emerges when looking at the net flows between each of the five zones. As shown in Figure 2, London's annual net outflow of 71 thousand to the rest of the country is primarily destined for the closest ring, with the OMA gaining some 50 thousand a year compared to some 16 thousand going directly from London to the OWSE and under 5 thousand to the Fringe. The reason why the OMA's overall within-UK migration balance is no larger than 5 thousand a year is because it loses nearly as many people to the rings further away as it gains from London. Again, distance is a factor here, as the main recipient of the OMA's net outflow is the next ring outwards. In its turn, the OWSE registers a net exodus to the remaining two rings while receiving net inflows from the OMA and directly from London, but in this case the total volume of the outward shift is much smaller than the total inflow from these two inner zones. Clearly, therefore, while there is an element of leapfrogging, this population redistribution is still taking place mainly through shorter-distance movement between adjacent places, just as in Ravenstein's day.

The between-zone relationships shown in Figure 2 can also be expressed in the form of the two sets of more precise measures defined in section 3.2. Looking first at the extent to which a place accommodates the deconcentration current, the absorption level works out at 9.6 percent for the OMA, based on its net migration gain from London of almost 51 thousand compared to its total net loss of 46 thousand to the three rings making up the rest of the country. By contrast, the level for the OWSE is much higher at 66 percent, derived from gaining 40 thousand from London and the OMA and losing just under 14 thousand to the two rings further out.

Turning to the transfer rate that identifies the zones most heavily involved in redistributing population across the WSE and beyond, it is the OMA that performs this role most clearly, with its net annual average inflow of almost 51 thousand com- 
Fig. 2: Net migration between the five rings, annual averages for 2001-2016

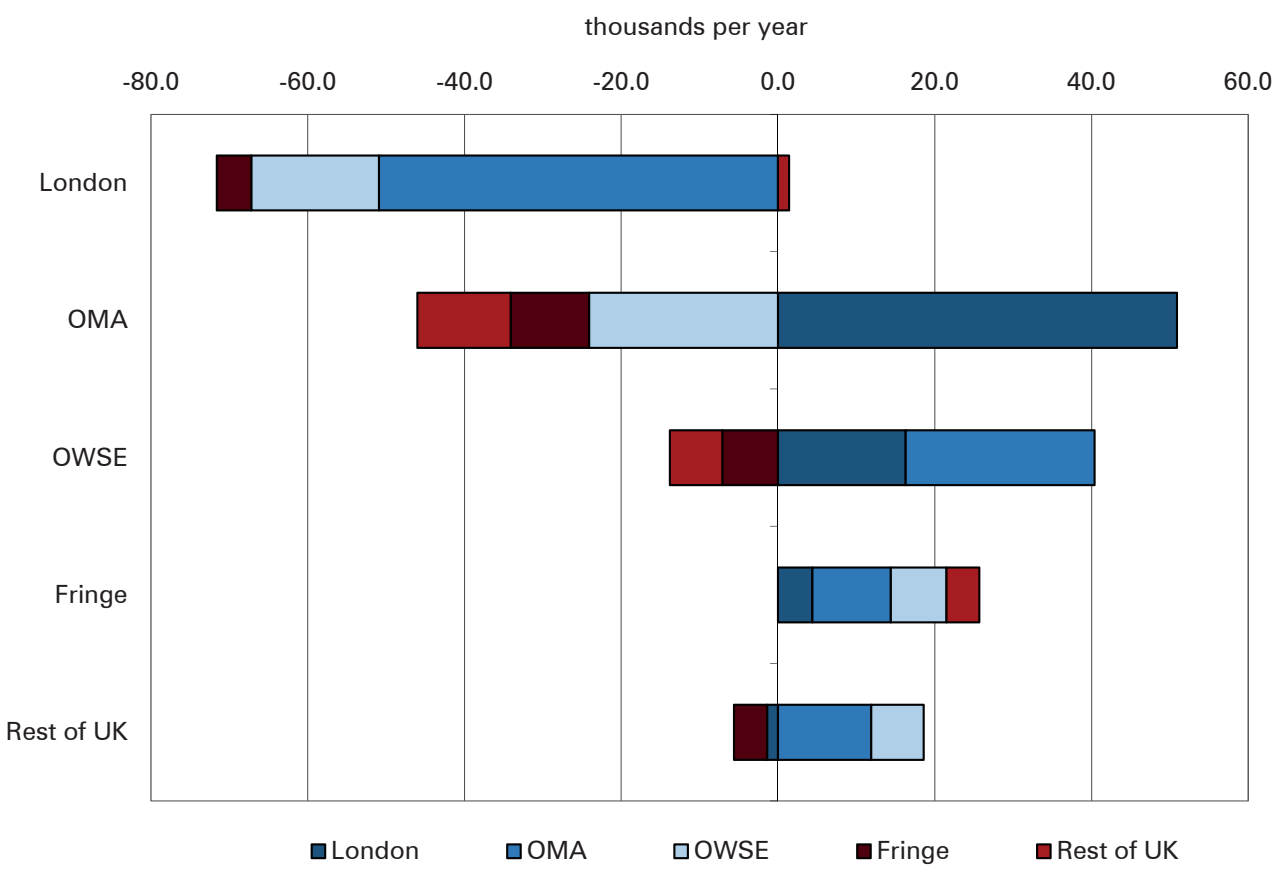

Source: own calculations from ONS data.

bining with its net outflow of 46 thousand to give a total population transfer that, when converted into a rate, comes to 16.1 per thousand of its total population. The equivalent rate for the OWSE is 7.3 per thousand and that for the Fringe 3.7 per thousand, revealing how far the degree of involvement in the deconcentration process declines with increasing distance from London. Of course, this conclusion is already evident from Figure 2, but the utility of these measures becomes more apparent when handling the larger number of areas that are distinguished at the TTWA level.

\subsection{The TTWA-level perspective}

Within the context of the London-centric zoning of the UK above, the paper now focuses in on the individual places that make up the WSE in order to identify their separate roles within the broad deconcentration current emanating from its core. As mentioned in section 3.2, this analysis is undertaken at the TTWA level rather than for the counties that Ravenstein's data forced him to use. In all, as shown in Figure 3, the WSE is composed of all or part of 45 TTWAs, with the part element referring to cases where the TTWA straddles the WSE boundary with the Fringe (for which the data used here are only for the part lying within the WSE). The TTWAs also overlap the zone boundaries to some extent, notably for zone 1: London TTWA extends beyond the Zone 1 boundary on the GLA's northern and eastern flanks but doesn't reach its western boundary where the separate TTWA of Slough \& Heathrow en- 
Fig. 3: The WSE's TTWA geography

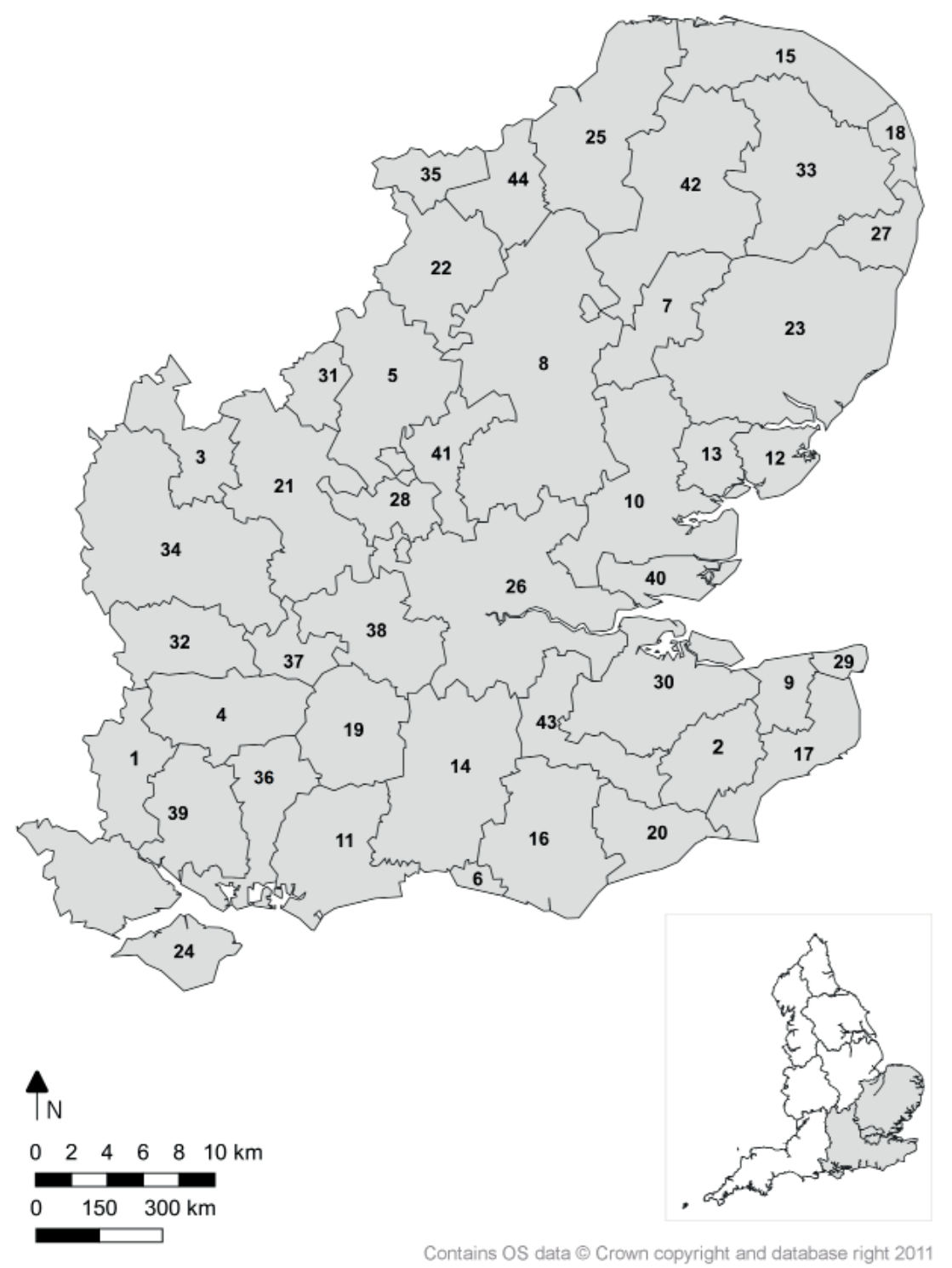

Note: The areas displayed here constitute the best fit of local government areas to the detailed geography of the ONS's 2011 TTWAs, see text. The name of each TTWA can be found from the first column of Table 2.

Source: based on the grouping of local authority areas devised by Gordon et al. 2018.

croaches on GLA territory. Together, these two London-based TTWAs can be seen to be the main driving force behind the WSE's deconcentration current, so the focus here is on how the other 43 TTWAs are involved in this. This goal is achieved by ap- 
plying the two concepts of transfer and absorption to the TTWA framework. The full dataset behind the following commentary is provided in Table 2 .

Looking first at the TTWAs' transfer role, it is found that all 43 have been contributing to the WSE's deconcentration current over the 15-year period ending June 2016. All 10 of the TTWAs located entirely or predominantly in the OMA received more migrants from London than they sent to it, i.e. they made a net gain from London. Perhaps even more impressively, every one of the 33 TTWAs located in the OWSE recorded an overall net gain from the two inner rings. Meanwhile, in terms of their migration exchanges with rings further away from London, all but three of the 43 TTWAs recorded a net outflow, the exceptions being on the outer edges of the OWSE, namely Cromer \& Sheringham, Brighton and Isle of Wight. But even in these three cases, the volume of net inflow from outside the WSE was much smaller than their net gains from the two inner rings, with the result that all 43 TTWAs were transferring more people to further away from London than towards it, as is shown by the "transfer volume" column in Table 2.

At the same time, the degree of involvement in the WSE's deconcentration current varies greatly between the 43 TTWAs. In the case of Cromer \& Sheringham, it amounted to an annual average population shift of just 448 during 2001-2016, less than one-twentieth of Luton's 9,200 at the other extreme. Besides the latter, seven other TTWAs transferred at least 5 thousand people a year, these being (in rank order) Crawley, Medway, Bedford, Chelmsford, Southend, High Wycombe \& Aylesbury, and Guildford \& Aldershot. Together, these 8 places contributed 57 thousand out of the 43 TTWAs' total transfer role of 119 thousand a year, i.e. almost half of it. Not surprisingly in view of the zone-level results discussed previously, these were predominantly representatives of the OMA, with just one (Bedford) located further away from London. As a corollary, the 11 TTWAs contributing least (less than one thousand a year) to the deconcentration current are all located in the OWSE and mainly in its outer reaches.

On the other hand, if using the population-standardised transfer rate to see how intensely each TTWA was involved in these transfers (Table 2), then the ranking is somewhat different. On this basis, top with an annual rate of 19.0 per thousand residents is Tunbridge Wells, which is also part of the OMA, with the OWSE's Bedford coming second with a rate of 17.4. The next 8 are Luton, Chelmsford, Clacton, High Wycombe \& Aylesbury, Crawley, Milton Keynes, Newbury, and Stevenage \& Welwyn Garden City, all with rates of at least 13 and therefore well above the WSE's annual average of 10 per thousand. Five of these are members of the OMA but the other three are located in the OWSE and indeed towards its furthest points from London, namely Clacton on the east coast, Newbury on the WSE's western boundary and Milton Keynes on its northwest edge. Interestingly, several of these TTWAs are centred on places that featured in the government's postwar programme of New and Expanded Towns for accommodating London's overspill.

Turning to absorption, as this is rather different conceptually from the transfer role (see section 3.2), it is not surprising to find that a TTWA can rank highly on transfer rate even if one of the two sets of net flows is very small. Clacton provides a clear example of this, because its fifth highest ranking on transfer rate (as just seen) 


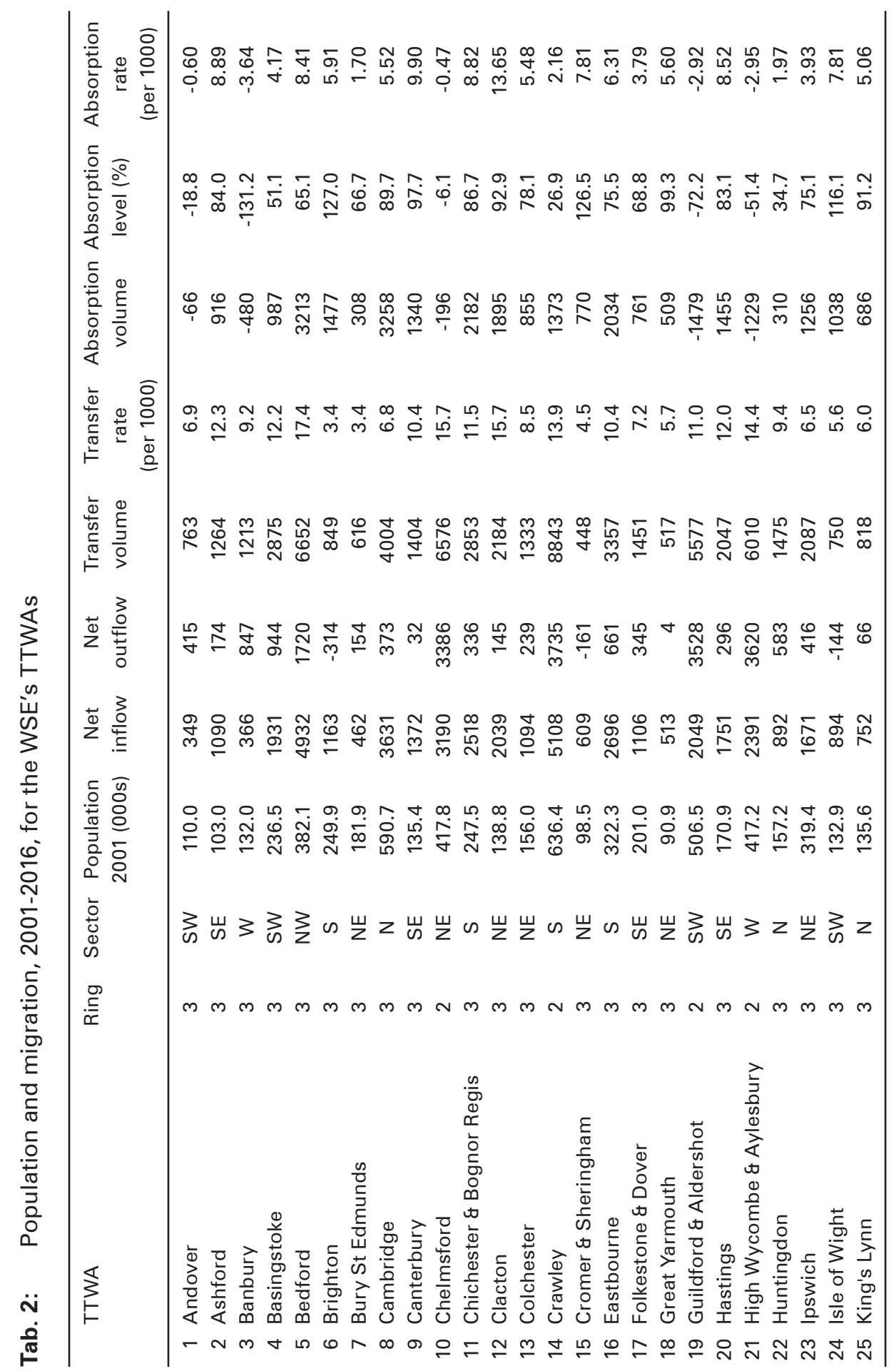




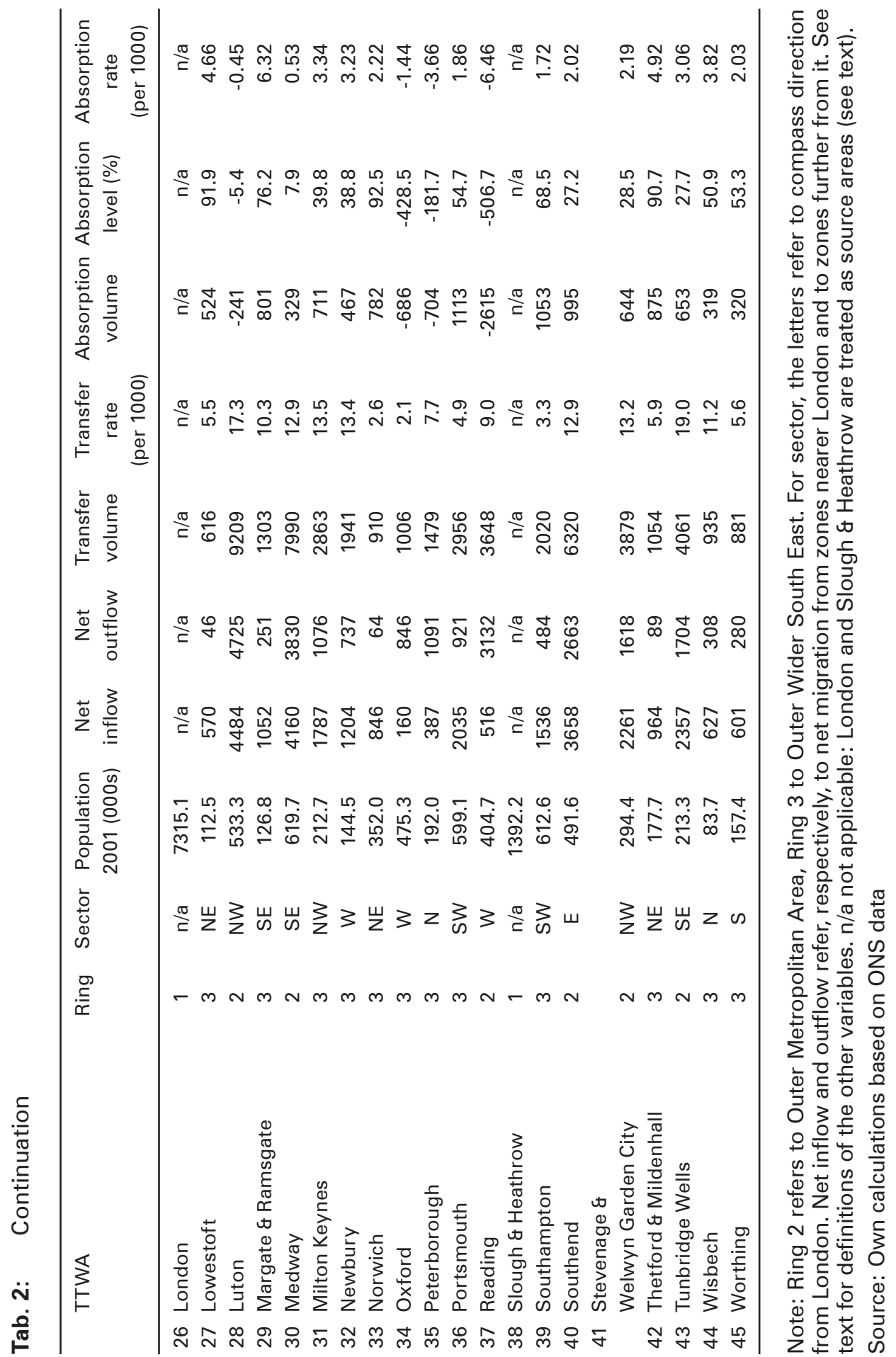


results almost entirely from its strong net inflow of over 2 thousand a year: its net outflow to outside the WSE is only 145 , meaning that it loses only 7 percent of its intake and has an absorption level of 93 percent (Table 2). In fact, there are more extreme cases than Clacton, notably the three TTWAs mentioned above that gain from the further-out rings as well as from those nearer London, namely Cromer \& Sheringham, Brighton and Isle of Wight, which thus exhibit absorption levels of over 100 percent. All of the others posting high absorption levels (90 percent and over) are, similarly, in coastal locations or are immediately adjacent to them: in descending order, Great Yarmouth, Canterbury, Clacton, Norwich, Lowestoft, King's Lynn, and Thetford \& Mildenhall.

At the other extreme on absorption level are two groups of TTWAs. As can be seen from Table 2, there are 9 where the absorption level is between 0 percent and 40 percent, meaning that for every 100 of net inflow from nearer London there is a net outflow of at least 60 to further from it. This group comprises (again in descending order) Milton Keynes, Newbury, Huntingdon, Stevenage \& Welwyn, Tunbridge Wells, Southend, Crawley and Medway. These are largely the mirror image of the high-absorption places, being generally away from the coast and closer to the WSE's landward boundary and thus with more opportunity for decanting residents into the Fringe and beyond. Medway on the Thames estuary is an exception to this rule, but - like several of the others in the list - it is part of the OMA with ample chance to shift people into the next ring outwards from London. Some New Towns also feature in the list, reinforcing their credentials as entrepôts for people or, in Ravenstein's terms, as "counties of passage".

The other 9 TTWAs that make up the bottom of this ranking are distinctive in their absorption levels being negative (Table 2). These are places where the net outflow to rings further away from London is larger than their net inflow from nearer London. Reading in the OMA is the extreme case, as while its migration exchange with London is rather evenly balanced (with just over 500 more people arriving from London than moving to it), its net loss to the OWSE and beyond totals over 3 thousand: This TTWA thus fails to absorb some 2600 people a year, five times its net inflow from London. The other 8 in this group are Andover, Banbury, Chelmsford, Guildford \& Aldershot, High Wycombe \& Aylesbury, Luton, Oxford and Peterborough. On this evidence, these 9 places are performing a role that is rather similar to the role played by the two TTWAs at the core of the region, in that they are helping to drive the WSE's deconcentration current. They include places that, like London, are characterised by stronger than average natural increase and net immigration from abroad, reflecting the fact that nowadays the WSE is not just a single-centred metropolitan region but a much more complex polycentric one that involves a degree of more localised population deconcentration (as noted by Hall/Pain 2006).

At the same time, these data do not directly measure the impact of the TTWAs' absorption role, so - as with the analysis of their transfer role - the numbers accommodated in this deconcentration process are translated into per capita rates (see final column of Table 2). By definition, the 9 TTWAs with negative absorption, just discussed, play no part in this, but at the other end of the scale it is Clacton that posts the highest rate of impact. Its absorption of almost 1,900 people a year over 
2001-2016 equates to a rate of 13.7 per thousand residents. Next highest (in order) come Canterbury, Ashford, Chichester \& Bognor Regis, Hastings, Bedford, Cromer \& Sheringham, Isle of Wight, Margate \& Ramsgate and Eastbourne, with rates of between 6 and 10 per thousand. Their dominant characteristic is that they contain seaside resorts that have for decades attracted retirement migrants and, with a consequently older than average age structure, experience a high mortality-driven population turnover rate that facilitates a large number of new arrivals without necessarily causing substantial overall population growth. Ashford, however, has no coastline but instead is a town that has grown rapidly in recent years, helped by being on the main route to the Channel Tunnel, while Bedford is distinctive in not only being in the WSE's far northwest but also performing a strong entrepôt function, as seen above.

Finally, the role which individual places play in the WSE's deconcentration current can be summarised by classifying them on the basis of their transfer and absorption rates together. Table 3 splits the 43 TTWAs into four groups according to whether each of these two rates is above or below the global average and also provides some locational information to help interpret the patterning. Perhaps the most distinctive group is that characterised by high transfer rate and low absorption rate, as these are predominantly located in the OMA (bottom left box of Table 3). This represents what might be called the pure form of Ravenstein's "counties of passage" within the deconcentration process, as previously seen for the OMA as a whole in Figure 2. Indeed, it can be seen that virtually all TTWAs located in the OMA are involved, irrespective of their radial sector out of London, the only exception being Reading which is classified as low on transfer rate as well as absorption rate. Also lubricating the process is Newbury, located west of Reading, along with Milton Keynes in the north-western sector.

Apart from Reading, the constituents of the other three groups in Table 3 are entirely composed of TTWAs in the OWSE, indicating the much greater variety of individual performances there. Like the group just discussed, the list headed by Ashford is a major player in receiving population from nearer London (i.e. from the OMA or directly from London itself) but accommodates a substantial proportion of this inflow rather than passing it on to rings further away. It is not surprising to find that many of these are coastal, with no further-out zone to send people on to. Similarly, coastal situations and high absorption rates dominate the list of places headed by Brighton, but their below-average transfer rates indicate that these play a less important role in the deconcentration process. Finally, the group that includes Reading has a low absorption rate, i.e. these TTWAs are essentially "counties of passage", but despite this they display low transfer rates and are thus performing this role for a relatively small net flow of people moving there from nearer London.

\section{Concluding discussion: Ravenstein then and now}

This paper has revisited territory - both geographical and conceptual - that Ravenstein examined in considerable detail in his work on the 1871 and 1881 Censuses. 
Tab. 3: Four-way classification of TTWAs based on their transfer and absorption rates

\begin{tabular}{|c|c|c|}
\hline \multirow{2}{*}{$\begin{array}{l}\text { Absorption rate } \\
\text { (average of } 3.37 \text { ) }\end{array}$} & \multicolumn{2}{|c|}{ Transfer rate (average of 9.54) } \\
\hline & Above average & Below average \\
\hline $\begin{array}{l}\text { Above } \\
\text { average }\end{array}$ & $\begin{array}{l}\text { Ashford ( } 3, \mathrm{SE}) \\
\text { Basingstoke ( } 3, \mathrm{SW}) \\
\text { Bedford }(3, \mathrm{NW}) \\
\text { Canterbury }(3, \mathrm{SE} \text {, coastal) } \\
\text { Chichester \& Bognor Regis (3, S, coastal) } \\
\text { Clacton ( } 3, \mathrm{NE} \text {, coastal) } \\
\text { Eastbourne (3, S, coastal) } \\
\text { Hastings (3, SE, coastal) } \\
\text { Margate \& Ramsgate ( } 3, \mathrm{SE}, \text { coastal) } \\
\text { Wisbech ( } 3, \mathrm{~N})\end{array}$ & $\begin{array}{l}\text { Brighton ( } 3, \mathrm{~S}, \text { coastal) } \\
\text { Cambridge }(3, \mathrm{~N}) \\
\text { Colchester (3, NE, coastal) } \\
\text { Cromer \& Sheringham (3, NE, coastal) } \\
\text { Folkestone \& Dover (3, SE, coastal) } \\
\text { Great Yarmouth ( } 3, \mathrm{NE} \text {, coastal) } \\
\text { Ipswich (3, NE, coastal) } \\
\text { Isle of Wight (3, SW, coastal) } \\
\text { King's Lynn (3, N, coastal) } \\
\text { Lowestoft ( } 3, \mathrm{NE} \text {, coastal) } \\
\text { Thetford \& Mildenhall }(3, \mathrm{NE})\end{array}$ \\
\hline $\begin{array}{l}\text { Below } \\
\text { average }\end{array}$ & $\begin{array}{l}\text { Chelmsford (2, NE, coastal) } \\
\text { Crawley }(2, \mathrm{~S}) \\
\text { Guildford \& Aldershot }(2, \mathrm{SW}) \\
\text { High Wycombe \& Aylesbury }(2, \mathrm{~W}) \\
\text { Luton (2 NW) } \\
\text { Medway }(2, \mathrm{SE} \text {, coastal) } \\
\text { Milton Keynes (3, NW) } \\
\text { Newbury (3, W) } \\
\text { Southend (2, E, coastal) } \\
\text { Stevenage \& Welwyn Garden City }(2, \mathrm{NW}) \\
\text { Tunbridge Wells }(2, \mathrm{SE})\end{array}$ & $\begin{array}{l}\text { Andover }(3, \mathrm{SW}) \\
\text { Banbury }(3, \mathrm{~W}) \\
\text { Bury St Edmunds }(3, \mathrm{NE}) \\
\text { Huntingdon }(3, \mathrm{~N}) \\
\text { Norwich }(3, \mathrm{NE}) \\
\text { Oxford }(3, \mathrm{~W}) \\
\text { Peterborough }(3, \mathrm{~N}) \\
\text { Portsmouth }(3, \mathrm{SW}, \text { coastal) } \\
\text { Reading (2, W) } \\
\text { Southampton (3, SW, coastal) } \\
\text { Worthing (3, S, coastal) }\end{array}$ \\
\hline
\end{tabular}

Note: In parentheses, 2 refers to Outer Metropolitan Area, 3 to Outer Wider South East; the letters refer to compass direction from London; "coastal" indicates being bounded by the Thames estuary, North Sea or English Channel. London and Slough \& Heathrow are treated as source areas and are therefore omitted (see text).

Source: derived from calculations based on ONS data.

The migration currents (and counter currents) that he identified for south-east England helped him to formulate his migration laws, most notably that most migration takes place over shorter distances between adjacent counties and in the form of a stepwise shifting of population from each county to the one next closer to the growing "centre of commerce and industry" that was London. Recognising that the main current of internal migration affecting this region is now centrifugal rather than centripetal, the aim has been to discover whether these two generalisations still hold in this very different context. To do this, the district-to-district migration flows for 2001-2016 were aggregated to, firstly, a London-centred zonation of the UK and, secondly, a subdivision of the WSE into approximations of official TTWAs.

The results provide strong support for the continuing relevance of these two laws. In spite of the initial evidence that the concentric ring to gain most from the deconcentration current emanating from London was not the immediately adja- 
cent OMA but the next two zones beyond it, a breakdown of the inter-zone net flows clearly demonstrated the dominance of shorter-distance population movements between adjacent zones over longer-distance leapfrogging across intervening zones. Additionally, Ravenstein's categorisations of counties of absorption and passage have prompted the development of quantitative measures of the extent to which places are involved in this deconcentration current. These have proved particularly useful for comparing the TTWAs in terms of how dynamic each is in receiving population from nearer London and the degree to which each has accommodated this net inflow locally as opposed to sending it further out across the WSE and beyond. A four-way classification based on differences in the TTWAs' transfer and absorption rates has pointed to key features that differentiate their role, with a particularly strong distinction being found between location in the OMA as opposed to in the OWSE and also with the level of absorption depending partly on whether or not they have a coastal border.

What this study has not examined in any detail are the direct drivers of the migration patterns observed, again following Ravenstein's emphasis on description and inference. As seen at the outset, his attempts at explanation focused almost exclusively on the workings of the labour market; in his words (1885: 198-199), "the mode in which the deficiency of hands in one part of the country is supplied from other parts where population is redundant" - with this driver operating primarily on a local basis such that a growing town draws labour from the surrounding area which then leaves gaps that are filled by migrants from more remote districts. In more modern parlance, it is the pull factor that powers the migration process via a vacancy chain and, while this serves an equilibrating function, it is dominated by quantity (i.e. the flow of job opportunities) rather than quality (i.e. skills or earnings). The $21^{\text {st }}$ century situation could be seen as the virtual antithesis of that interpretation, with its prevailing current of counterurbanisation being driven by the push of growing housing demand in London which cannot all be met locally, thereby powering a displacement chain. Price effects are key to the latter, with the new households arising from natural increase and migration from abroad (plus extra space demands arising from local residents' income growth) generating pressures that forces or encourages residents to move outwards. These effects depend on an inelastic local housing supply and this is the case not just in the booming centre but also further out in and beyond the Green Belt where new building is restricted to a greater or lesser extent.

Yet, despite these very different circumstances, it is perhaps not very surprising that Ravenstein's first two laws still apply in the WSE. Whereas it is now recognised that the most long-distance migration is job-related, the vast majority of housing-related moves tend to be relatively short-distance (Gordon 1982). Indeed, most would normally take place within the confines of the individual TTWAs used in this analysis, but the WSE is not normal in this context, with the pressures emanating from London transcending what is no doubt also occurring at a more local level across the region. As just suggested (and as clearly documented decades ago by Hall et al. 1973), planning controls have widened the area of housing-supply unresponsiveness while transport improvements have enabled London's jobs to be 
accessed from further away. In sum, inflexibilities built into the housing market now form a critical part of the WSE's whole migration system.

That said and while acknowledging that considerable job growth has also been occurring in the towns and cities of the OMA and OWSE, it is primarily through the lens of the housing market that further research is needed for identifying, and measuring the effect of, the factors directly involved in fashioning the patterning of the flows that comprise the WSE's deconcentration current. At the same time, given the striking similarities between the $19^{\text {th }}$ and $21^{\text {st }}$ centuries observed here despite internal migration switching from centripetal to centrifugal patterning, the findings provide ample confirmation that there is something fundamental about the friction of distance for human behaviour, not withstanding the major developments in transport and communications that have taken place over the past 130 years. Conceptually, this raises a question as to how deeply Zelinsky's (1971) mobility transition model penetrates into the micro-level aspects of migration decision making as opposed to the waxing and waning of the various types of migration over the transition period, especially the ongoing debate as to how adequately that model can incorporate the switch from urbanisation to counterurbanisation (Greenwood 2019).

\section{Acknowledgements}

I am very grateful to lan Gordon for allowing me to draw on the population and migration databases that we developed for the report Migration Influences and Implications for Population Dynamics in the Wider South East (Gordon et al. 2018). I am also indebted to lan for providing the map in Figure 1 and to Caitlin Robinson for preparing Figure 3. Thanks also go to Special Issue Guest Editors Philip Rees and Nikola Sander for inviting this contribution and to Philip and two anonymous referees for their constructive and insightful comments and advice. Any errors and omissions that remain are, however, entirely the author's own.

\section{References}

Boyle, Paul; Halfacree, Keith (Eds.) 1998: Migration into Rural Areas: Theories and Issues. Chichester: John Wiley \& Sons.

Champion, Anthony G. 1989: Counterurbanization: The Changing Pace and Nature of Population Deconcentration. London: Edward Arnold.

Champion, Tony; Atkins, David 1996: The Counterurbanization Cascade: An Analysis of the 1991 Census Special Migration Statistics for Great Britain. Seminar Paper 66, Department of Geography. University of Newcastle upon Tyne.

Champion, Tony 2002: The Containment of Urban Britain: Retrospect and Prospect. Milan: FrancoAngeli.

Champion, Tony 2005: The Counterurbanisation Cascade in England And Wales since 1991: The Evidence of a New Migration Dataset. In: BELGEO 2005 1-2: 85-101 [doi: $10.4000 /$ belgeo.12440]. 
Champion, Tony; Coombes, Mike; Gordon, lan 2014: How Far Do England's SecondOrder Cities Emulate London as Human-Capital 'Escalators'? In: Population, Space and Place 20: 421-433 [doi: 10.1002/psp.1806].

Champion, Tony 2016: Internal Migration and the Spatial Distribution of Population. In: Champion, Tony; Falkingham, Jane (Eds.): Population Change in the United Kingdom. London: Rowman and Littlefield International: 125-142.

Coombes, Mike; Charlton, Martin 1992: Flows to and from London: A Decade of Change. In: Stillwell, John; Rees, Philip; Boden, Peter (Eds.): Migration Processes and Patterns Volume 2 Population Redistribution in the United Kingdom. London: Belhaven: 56-77.

Fielding, Anthony J. 1992: Migration and Social Mobility: South East England as an 'Escalator Region'. In: Regional Studies 26,1: 1-15 [doi: 10.1080/00343409212331346741].

Fielding, Anthony J. 1993: Migration and the Metropolis: An Empirical and Theoretical Analysis of Inter-regional Migration to and from South East England. In: Progress in Planning 39,2: 71-166 [doi: 10.1016/0305-9006(93)90006-F].

Gordon, lan R. 1982: The Analysis of Motivation-Specific Migration Streams. In: Environment and Planning A 14,1: 5-20 [doi: 10.1068/a140005].

Gordon, lan et al. 2018: Migration Influences and Implications for Population Dynamics in the Wider South East. London: LSE London [http://lselondonhousing.org/wp-content/ uploads/2018/01/EELGA-Migration-Project_Main-Report_plusExec.pdf, 07.01.2020].

Greenwood, Michae/ J. 2019: The Migration Legacy of E G Ravenstein. In: Migration Studies 7,2: 269-278 [doi: 10.1093/migration/mny043].

Hall, Peter et al. 1973: The Containment of Urban England, Volume 1, Megalopolis Denied. London: George Allen and Unwin.

Hall, Peter; Pain, Kathy 2006: The Polycentric Metropolis London: Earthscan.

Lee, Everett S. 1966: A Theory of Migration. In: Demography 3: 47-57 [doi:

10.2307/2060063].

Lomax, Nik; Stillwell, John 2018: United Kingdom: Temporal Change in Internal Migration. In: Champion, Tony; Cooke, Thomas; Shuttleworth, lan (Eds.): Internal Migration in the Developed World: Are We Becoming Less Mobile? London: Routledge.

ONS 2016: Travel To Work Area Analysis in Great Britain. London: Office for National Statistics [https://www.ons.gov.uk/employmentandlabourmarket/peopleinwork/employmentandemployeetypes/articles/traveltoworkareaanalysisingreatbritain/2016, 10.10.2019].

ONS 2019: Population Estimates for the UK, mid-2018: Methods Guide. London: Office for National Statistics [https://www.ons.gov.uk/peoplepopulationandcommunity/ populationandmigration/populationestimates/methodologies/methodologyguideformid2015ukpopulationestimatesenglandandwalesjune2016, 07.01.2020].

Plane, David A.; Henrie, C. J.; Perry, M. J. 2005: Migration Up and Down the Urban Hierarchy and Across the Life Course. In: Proceedings of the National Academy of Sciences 102: 15313-15318 [doi: 10.1073/pnas.0507312102].

Ravenstein, Ernest George 1876: The Birthplaces of the People and the Laws of Migration. London: Trübner \& Co.

Ravenstein, Ernest George 1885: The Laws of Migration. In: Journal of the Statistical Society of London 48,2: 167-235 [doi: 10.2307/2979181].

Ravenstein, Ernest George 1889: The Laws of Migration. Second Paper. In: Journal of the Royal Statistical Society 52,2: 241-305 [doi: 10.2307/2979333]. 
Stillwell, John; Rees, Philip; Boden, Peter 1992: Internal Migration Trends: An Overview. In: Stillwell, John; Rees, Philip; Boden, Peter (Eds.): Migration Processes and Patterns Volume 2 Population Redistribution in the United Kingdom. London: Belhaven: 28-55.

Zelinsky, Wilbur 1971: The Hypothesis of the Mobility Transition. In: Geographical Review 61: 219-249.

Prof. Dr. Tony Champion $(\varangle)$. Centre for Urban and Regional Development Studies (CURDS), Newcastle University. Newcastle upon Tyne, United Kingdom.

E-mail: tony.champion@newcastle.ac.uk

URL: https://www.ncl.ac.uk/gps/staff/profile/tonychampion.html\#research 


\section{Comparative Population Studies}

WWW.comparativepopulationstudies.de

ISSN: 1869-8980 (Print) - 1869-8999 (Internet)

\section{Published by}

Prof. Dr. Norbert F. Schneider

Federal Institute for Population Research D-65180 Wiesbaden / Germany

\section{(c) BY-SA}

2019

\section{Managing Editor \\ Prof. Philip Rees \\ Dr. Katrin Schiefer}

\section{Copy Editor}

Julia Luther

\section{Editorial Assistant}

Beatriz Feiler-Fuchs

Wiebke Hamann

\section{Layout \\ Beatriz Feiler-Fuchs \\ E-mail:cpos@bib.bund.de}

\section{Scientific Advisory Board}

Karsten Hank (Cologne)

Michaela Kreyenfeld (Berlin)

Marc Luy (Vienna)

Natalie Nitsche (Vienna)

Peter Preisendörfer (Mainz)

Zsolt Spéder (Budapest)

Rainer Wehrhahn (Kiel)

\section{Board of Reviewers}

Martin Abraham (Erlangen)

Laura Bernardi (Lausanne)

Hansjörg Bucher (Bonn)

Claudia Diehl (Konstanz)

Andreas Diekmann (Zurich)

Gabriele Doblhammer-Reiter (Rostock)

Jürgen Dorbritz (Wiesbaden)

Anette Eva Fasang (Berlin)

E.-Jürgen Flöthmann (Bielefeld)

Alexia Fürnkranz-Prskawetz (Vienna)

Beat Fux (Salzburg)

Joshua Goldstein (Berkeley)

Sonja Haug (Regensburg)

Hill Kulu (Liverpool)

Aart C. Liefbroer (The Hague)

Kurt Lüscher (Konstanz)

Emma Lundholm (Umeå)

Nadja Milewski (Rostock)

Dimiter Philipov (Vienna)

Roland Rau (Rostock)

Tomáš Sobotka (Vienna)

Jeroen Spijker (Barcelona)

Olivier Thévenon (Paris)

Helga de Valk (Brussels)

Heike Trappe (Rostock)

Michael Wagner (Cologne) 